\title{
Macro and Micro Strategies to Stimulate Students' Criticality
}

\author{
Maya Gunawardena \\ UNSW Canberra, Australia
}

\begin{abstract}
Critical thinking (CT) is a long lasting legacy in higher education. Thus university academics strive to cultivate disciplinary based $C T$ in their disciplines. Such a task is equally challenging in postgraduate and undergraduate courses. This study investigated macro and micro strategies that academics adopt in their teaching and assessment to enhance students' $C T$ at one university in the schools of Physical Sciences, Engineering, Humanities and Business. The study included 20 interviews with academics and the qualitative analysis of their summative and formative assessment tasks. The study shows that CT is an essential transferable and a meta-cognitive skill that helps transforming students to be workplace ready. The study identifies that formative assessment and continuous teacher feedback and reflective learning tasks as major contributors in developing self-directed learning. The study also indicates several teacher-related and student-related challenges in developing holistic thinking with a subtle shift between scaffolded and independent learning and negotiating students' limited critical reading skills and written skills in argumentation.
\end{abstract}

\section{Introduction}

Cultivating critical thinking, undoubtedly, is a key priority [28] and the long lasting legacy in higher education [25]. Humans make numerous professional or personal decisions that indeed impact on others or institutions surrounding them. Thus, in higher education disciplines, the current attempt is to move away from using conventional curriculum strategies and to explore possibilities to develop newer and better strategies that facilitate and foster self-directed learning [26]. Current research in education has contributed much to understand critical thinking, its pedagogy and strategies for assessment. However, what instructional paradigms could best facilitate students' critical thinking in the disciplinary enculturation process is still an ongoing discussion.

Enculturation is the process by which an individual learns the traditional content of a culture and assimilates its practice and values [20] and in academic disciplines instructors have a similar duty to help students understand the disciplinary concepts to apply them in making decisions and solving problems in their contexts and become scholars in a particular field. For example, an engineering student learns and acquires subject knowledge specific to engineering and applying engineering concepts and theories. His solution to a problem can be specific and different to that of an economics student. Hence, experts in academia today attempt to provide both subject specific knowledge and opportunities to cultivate critical thinking skills for inquiry, dialogue and real life application. Moreover, cultivating critical thinking is required in higher education [7].

The burgeoning literature, most in the 1980s and 1990 s, advocates the necessity for cultivating both disciplinary [12] and generic critical thinking skills [9], but little is known about the instructional interventions driven by the subject content, context and student related factors. Although, Sternberg [32] argues that searching for the best or one particular approach is a teacher fallacy, current innovations [9], [5] in teaching indicate that some strategies are more effective than others. Experimental studies have examined the effect of various teaching strategies and test measures by employing quantitative research designs including pre-test and post-test protocols, but findings are inconclusive [2]. This paper therefore reports on a qualitative study that investigated academics' perspectives on role of critical thinking, pedagogic strategies and assessment procedures adopted in cultivating critical thinking skills in academic enculturation. Further, it will critically examine the suitability of the synchronous and asynchronous strategies discussed by the participants of this study in their pedagogic interventions and investigate how these activities contribute to cultivate critical thinking in across disciplines.

\section{Literature review}

\subsection{Critical thinking and its role in academia}

Existing diverse definitions and dichotomous views about critical thinking make it more difficult to be applied in contexts. Scholars such as Ennis [11], [12] have interpreted critical thinking to be a generic skill. Ennis describes critical thinking as "reasonable, reflective thinking focused on deciding what to believe or do" [11]. As adults, we have noted how sophisticated some children can be when they engage in "reasonable reflective thinking" when completing a simple project or also how, interestingly, some farmers with little or no formal education take their wise and apt decisions by considering factors available to them. These examples indicate that humans instinctually have some level of critical thinking, before they are taught 
to enhance it. However, research identifies that critical thinking is not a fixed entity and it has to be fostered and developed ([12], [15], [29], [31]), for students to view the world with a better understanding and to face current global demands and challenges.

As critical thinking has been identified as a long lasting legacy in higher education, disciplinary specific academics try to embed critical thinking in their teaching. Research has found distinct differences between domain specific critical thinking [24] and argues teaching critical thinking in each discipline can vary based on subject specific needs [25]. Ennis [12] clarifies the subject specific critical thinking and illustrates the paradox of "generic critical thinking" skills because critical thinking cannot be developed without content. Whether critical thinking is generic or domain specific is an ongoing debate [25] and therefore, investigation of teacher cognition [4] and their practice in disciplines is a useful endeavor to increase our understanding. Studies indicate that while subject specific knowledge is necessary for critical thinking, it does not necessarily facilitate students to think critically unless they are taught to do so [14]. Therefore, tertiary pedagogy needs improvement in its design and implementation to enhance students' critical thinking skills.

Recent studies show development in university students' critical thinking but "...we do not have much information about how students develop critical thinking" [23]. Despite all the effort, as Cameron [5] argues, the biggest challenge in academia even today is students' poor or little knowledge of critical thinking. This deficiency in academia is well-known and many attribute the problem to students' lack of understanding of subject specific knowledge. However, experimental research indicates that the above is a misperception or a false assumption as students who demonstrate subject knowledge fail to adopt their knowledge to think critically in problem solving scenarios [22]. These findings suggest the need for academics to use effective and innovative strategies to enhance students' critical thinking skills. Present study is an attempt to examine what academics value and practice in their teaching.

\subsection{Strategies to enhance critical thinking skills: Evidence from literature}

As Daley et al. [8] argue developing effective instruments for teaching and measurement to foster critical thinking is challenging. Research and practice in higher education acknowledge that traditional knowledge based acquisition strategies do not contribute to cultivating adequate levels of critical thinking skills [31], [26). Barnett [2] claims that even though academics are in favour of critical thinking, they have "no proper account of it". While some explicitly teach critical thinking, others expect students to nurture thinking implicitly while taking opportunities provided in their courses [23]. Ordinary thinking is different from critical thinking [1], [21] and therefore, instructors need to include activities to develop the critical thinking skills necessary to understand the developing trends in specific disciplines. Ennis [12] argues that academics could easily distinguish between students demonstrating and not demonstrating critical thinking skills in their work. Students demonstrate a higher level of critical thinking skills think logically, analyzing the given content or situation systematically and arriving at appropriate perceptions or decisions. They are also open minded and ready to change their positions based on the dictated evidence [12].

Objective formative tests only promote developing subject matter knowledge but they do not necessarily promote criticality in learning. Even some problem solving tasks do not necessarily promote the required level of critical thinking skills as the tasks can be within the domains of low and instrumental level [2]. Barnett states that in order to help students to be critical beings, the academic should help them to become transformatory critiques and to expand their scope based on knowledge, self and world. It is argued that students often find it difficult to apply knowledge beyond their scope and transfer knowledge when necessary for critical thinking [16]. Moreover, in his book 'Thinking Fast and Slow', Daniel Kahneman [17] explains different paradigms such as brain patterns, heuristics in thinking can impact on making fast decisions. Kahneman also raises an important aspect of human thinking where speed of decision making is important in certain occasions such as avoiding accidents, air traffic controlling, reaction at a natural disaster and other occasions where quick effective decisions are necessary.

Argumentative or debatable topic analysis often helps students to direct their thinking in different directions by examining counter, pro arguments and their premises [8]. These kinds of activities enhance student critical thinking skills. Twardy [33] illustrates a computer based argument mapping approach that he adopts in his teaching. He argues that often students get confused "with multi- premise reasons with multiple reasons" thus argument mapping exercises allow students to identify claims and lines of reasoning to assess evidence and support. However, research shows little about how, when and where academics can adopt this approach to enhance critical thinking skills.

The problem solving approach is also increasingly becoming popular in many disciplines such as engineering, mathematics and other science based areas [5]. One of the biggest challenges in this 
approach is that of designing a problem where students can demonstrate both subjects' knowledge and their abilities for critical thinking [22] In his study, Lythcott found that students could solve problems following prescriptions "in a rote fashion" without using chemistry knowledge; thus she alerts academics to use problem solving more purposefully to develop critical thinking in chemical engineering. This tension and a lack of understanding of the different impacts of the problem solving approach can negatively affect students' learning. Thus, Norman and Schmidt [26] suggest that more research in this area would be beneficial. However, even after a decade, we have little evidence for the success of the problem solving approach. Another vital concern is students' ability to transfer specific knowledge to solve common problems.

One other challenge that academics face today is to promote higher order thinking skills in online virtual classroom environments. MOOCS courses and online distant learning modes are becoming popular in Australia. Increasing numbers of students choose to study online, but only some academics are capable of facing the challenge as they are equipped with skills and strategies to provide opportunities to develop higher order thinking similarly to the face to face teaching. Computer conferencing and other asynchronous and synchronous tasks such as textbased interaction can contribute to develop these skills [23]. However, there is little evidence of the effectiveness of these approaches. More research is needed to investigate tensions and challenges that teachers and students face in dealing with these tasks.

Despite its heightened significance in graduate attributes in Australia, pedagogies for critical thinking have been given little attention, seemingly assuming any intervention would facilitate students' criticality. Fox [13] proposes teacher-initiated versus student-initiated teaching theories and this classification indicates that teachers seem to develop their pedagogy by working with students and reflecting on the perceptions they develop over time about student learning. Research about how academics cultivate students' critical thinking skills in their teaching and in the way they design their assessment tasks is scare. Such research would indeed provide good practice principles that could be adopted universally and reveal constraints and challenges in disciplinary teaching. This study was conducted aiming to address this need.

\section{Research questions}

The study was basically focused on the following research questions:

1. What instructional strategies are used for CCT in academic disciplines?
2. What assessment strategies are used to assess developing CT skills?

3. What challenges are encountered in CCT in the higher education context?

\section{Methodology of the study}

This paper reports on a mixed methods study that adopted 20semi-structured interviews with experienced academics from four schools (four informants from Physical Sciences, five from Engineering, five from Humanities, four from the School of Business and another two from interdisciplinary backgrounds) in a leading university in Australia. The major aim of the semi-structured interviews was to enable academics to describe their pedagogical interventions, assessment procedures and their tensions and challenges in regard to developing critical thinking, particularly in their disciplines. The interviews were audio recorded, transcribed and analysed using semantic analysis.

Interviews are useful tools in qualitative research as they are more grounded and they allow the researcher to elicit human experience, viewpoints and attitudes towards a certain social concept. As Cohen et al. [6] note, "Interviews enable participants - to discuss their interpretations of the world in which they live, and to express how they regard situations from their own point of view". Therefore, researchers can find out what people commonly believe and they gain valuable insights into the important issues regarding a particular concept or topic. Interviews may be invaluable in some research studies depending on the specific research objectives. As Tuckman notes, interviews provide access to "what is inside a person's head" and make it possible to measure what a person knows (knowledge or information), what a person likes or dislikes (values and preferences) and what a person thinks (attitudes and beliefs).

In addition, 15 critical thinking focused assignments were analysed making judgments about the cognitive and other related skills involved in completing them. The main purpose of this analysis is to examine how academics structure these tasks, scaffold or not scaffold them, weigh and plan for evaluation of critical thinking skill. Data were recorded on a spread sheet for further interpretations.

\section{Results}

\subsection{Academics' perspectives of critical thinking and its role in their disciplines}

Unanimously, all the participants highlighted the crucial need for students developing critical thinking in their disciplines and teachers do not expect their students to regurgitate the subject content 
uncritically. There are commonalties in the process in which teachers develop critical thinking in different disciplines and also differences in the way students arrive at solutions for specific questions and evaluate them. However, the academics in each discipline value critical thinking equally and believed that they could apply similar pedagogies across disciplines, despite the difference in the delivery of subject matter. Many informants argued that students need critical thinking in "application of theory or concepts in practice" and therefore a necessary cognitive skill in learning. However, the degree to which the skill is focused in learning would depend on the course purpose. For example, an informant who teaches basic accounting concepts said that she has little attention for critical thinking in the first course which is based on theory and more attention in the second course which is for application. Another informant from physical sciences said that she uses a similar approach depending on the focus of the course.

Students' skills for critical thinking are equally valued in all disciplines. They are required to have academic specific knowledge and also the ability to transfer the knowledge into the general social context. "So they need to have critical aptitude and knowledge" (P. 3). For example, one would assume that engineering involves many mathematical calculations which is the case most of the time but in reality engineering designs operate considering different paradigms; as one participant emphasised "they (engineers) will often be placed in situations where they won't know the answer and they won't have been taught the answers .... They're not going to get the answer out of a textbook" (P 1). This situation is similar in Business, Geography, Social sciences and Mathematics. P 2 raised his concern about learning business concepts and developing criticality is important as "business practice is very ephemeral ... Tends to operate on a day to day basis".

Similarly, students need to be able to critically analyse literature in all the fields to be able to understand how concepts are practically used in research and community. P 4 (a participant from Humanities) stated that critical thinking is basically;

\section{...very much about someone making a judgment about whether they agree with something and the reasons for which they agree with a particular point of view, or indeed advance a new view based on the other things that they looked at. (P 4)}

One major characteristic of critical thinking is students' ability to reflect on an argument demonstrating "critical reflective thinking incorporates the capacity to evaluate completely new ideas without prejudice or without bias or without pre-judging them". Participant 5 further analysed critical reflective practices as being "partly about being logical and consistent in the way that you analyse something, but an important part of that is being open to new ways of thinking". Moreover, often students are required to analyse data and make inferences from them. So critical thinking is crucial in these circumstances. Participant 5 stated "much of the work that I do to try and promote critical thinking surrounds the issues of use of data and choices that the analyst would make around how they're using that data". So critical thinking is "thinking out of the box resourcefully". Informants in this study unanimously agreed with the crucial role played by critical thinking skills and suggested that academics must use effective strategies to cultivate these skills in their subjects. They saw a distinction between students' ability to think critically and having good subject knowledge.

\subsection{Main text}

While many informants raised the need for students becoming independent and innovative in their learning, they consistently agreed with the crucial role that academics play in strategizing their pedagogy to stimulate students' criticality. About $60 \%$ of the informants in this study believed that course structure or the order in which subject items are presented in a course help to develop students' rational thinking and understanding of course concepts. The study did not identify any domain specific structures but teachers seem to use an approach similar to Bloom's taxonomy. In fact, about $30 \%$ recalled Blooms' principles as effective ways to organize teaching.

Apart from the course structure, macro and micro strategies that many use in their teaching promote thinking skills. Some dominantly mentioned tasks across all disciplines were field trips, demos, debates in class, group discussions, teacher student interaction/online forums, guest lecturers/experts, problem solving/brainteasers, stimulus response videos and critical reading tasks accompanied by critical reading questions. Some widely used assessment tasks were group challenges, problem solving, argumentative and expository essay questions, case study analyses, reflective writing, peer reviews, presentations, and critical reviews, reading tasks, role plays/simulations, E-portfolios and synoptic essays. Most of these tasks involve student interaction and high level thinking skills.

Most participants believed that assessment tasks carry more weight in developing critical thinking skills and developing an effective task was time consuming. They found that their students pay more attention to assignment and try to perform better to obtain marks. Hence, many academics embed critical 
thinking in their assessment tasks which clearly demonstrates the need for showing critical thinking skills in their marking criteria or rubrics. Major tasks include writing case study reports, take-home essays, and closed book in-class essays, reflective journal reports about students' own learning, synoptic essays, article reviews and relevant problems solving tasks. These tasks require higher level reading and interpreting skills and also effective written communication skills.

\subsection{Tensions and challenges}

One of the interview questions inquired about the challenges that academics encounter in developing critical thinking in their disciplines. Some of these challenges were also referred to when academics discussed their pedagogies. Figures 1 and 2 show the percentages of student and teacher related challenges discussed in the interviews.

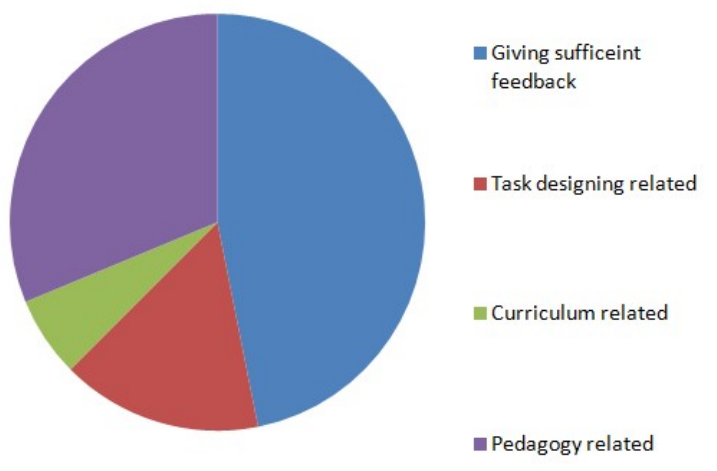

Figure 1. Teacher related challenges

As demonstrated the majority of academics in this study faced difficulties in giving students feedback and designing effective tasks to cultivate critical thinking and they find majority of their students' skills and experience in higher level learning are limited. Particularly, P 13 said: "so a constant challenge for me is trying to find a way to make it less of a burden on me... by giving more efficient feedback". The majority were not sure whether their feedback was effective for students' learning.

The majority identified that paying conscious effort to include tasks for critical thinking is useful as there is a possibility for some academics only to concentrate on the subject content.

The majority of informants wanted to find out whether their strategies are effective or other academics use better strategies in their disciplines that facilitate critical cultivation of critical thinking.

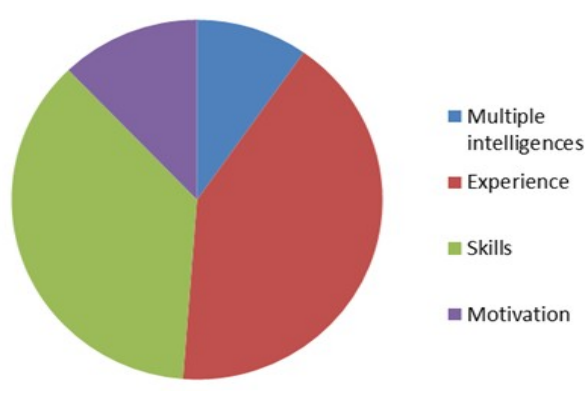

Figure 2. Student related challenges

That's why it's really important to teach it (critical thinking) when you do have the opportunity because you don't want a student going through their entire Engineering degree and not being able to think critically, but it's theoretically possible to do that. $(P$ 1)

\section{Discussion}

This study has identified several significant findings about how critical thinking is cultivated through macro and micro pedagogical and assessment strategies. The study shows that critical thinking is a multidimensional and multifaceted skill and therefore students need to develop both generic and disciplinary focus critical thinking to become holistic learners. This finding also shows that it is difficult to divorce disciplinary thinking from generic critical thinking. This study did not find any domain specific approaches: most of macro and micro pedagogical tasks exploited across all disciplines. The participants in this study believed that students who developed both generic and specific skills can transfer knowledge and apply critical thinking when necessary. Those who only developed disciplinary thinking find it difficult to apply knowledge in other contexts. So critical thinking is "transferable and generalizable" [27] Hence, critical thinking is not just a cognitive skill but a metacognitive enterprise that needs cultivation. If academics only consider disciplinary concepts without prompting students to think holistically, their thinking may be inadequate or faulty. As [16] argues students engage in faulty thinking, they cannot transfer critical thinking across domains. Halpern's 'faulty' thinking is the mechanical and formulaic thinking where students' thinking is restricted. The problem solving tasks in mathematics and engineering and other science based subjects have further confirmed that critical thinking is a metacognitive exercise which involves both generic 
and disciplinary knowledge. Polya [36] suggests a question based approach in promoting critical thinking to solve problems. Hence, teachers demand "time, practice, devotion and sound principles" to encourage effective holistic thinking.

Academics believe that critical thinking is essential as it has always allowed researchers to direct a new line of thinking. In academic enculturation, students are encouraged to think like academics. Critical thinking is students' ability to analyse the given content or the issue in-depth, examining explicit and implicit information to advance a new idea or an argument or a perspective by providing valid and reasonable evidence considering every related aspects of the content or the issue. Thus, students' need to let their mind become a moving prism and a critical thinker approaches materials with a critical attitude and directs his/her thinking based on the context given and examines connections and messages that are obvious and implied to form a new line of rational thought or a cohesive, coherent and cogent argument.

Furthermore, the study shows that the course structure and the lesson structure help students develop rational thinking when processing information in a hierarchal order such as in the Blooms' taxonomy. Human thought is structure sensitive and thus, the structure in which the information is processed allows students to develop relational knowledge. The process delivering courses help developing relational thinking which is fundamental in academic domains. According to Bloom's taxonomy, students' understanding of a particular concept is enhanced through several processes. In addition to Blooms steps, this study shows that self-reflective activities, such as the synoptic essays, play a key role in helping students to make connections with knowledge, pragmatics and application. Thus, academics should ensure that they help their students to reflect of on their learning by adopting effective strategies.

As also confirmed by Barnett [2] the study shows the risks of academics being only concentrate on the subject specific knowledge. They can only focus on developing subject knowledge. Therefore, explicit focus for critical thinking is essential in learning. Kennedy et al. [19] claim that bad teaching neglects critical thinking in learning. As demonstrated in the assessment tasks analysis, the stimulus plays an important role in cultivating critical thinking. These stimuli can be a problem, a case, a question, a scenario, an argument topic or a research paper or any other kind. In responding to the given stimuli, students are expected to think holistically in a particular domain. They require numerous skills in reading, interpreting, analyzing and writing. If students' confront issues with such skills, they may not demonstrate deep thinking. As the outcomes of critical thinking can vary from student to student, academics seem to find it difficult to help students to direct their thinking.

Teacher feedback about students' work is vital in developing critical thinking [30]. However, opportunities are very limited for students to act on feedback. Most formative and summative assessment tasks are completed with the action of teacher feedback and evaluation (see figure 3). This allows no opportunity for students to respond to feedback which is a major concern of the participants in this study. Figure 4 highlights one other significant process that completes the holistic learning process through reflecting on teacher feedback. This shows the need for closing the feedback loop. E-portfolios, peer review essays and the argument mapping essay tasks allowed students to act on feedback as they receive feedback before their final submission or they get regular feedback. In e-portfolios, students upload their responses for teacher to provide feedback and then, the portfolios are expanded or revised based on the teacher feedback. One of the concerns regarding this exercise is that teachers' need to spend extensive time by providing individual feedback for large classes.

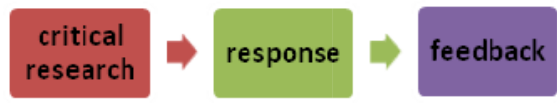

Figure 3. Linear assessment structure

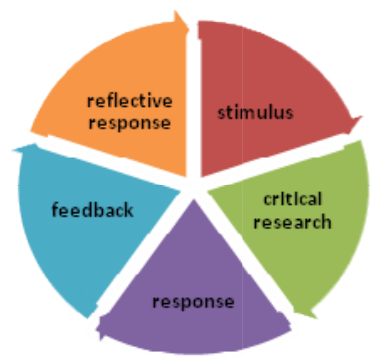

Figure 4. Circular assessment structure

These results suggest the strong emphasis on the effective use of formative assessment. The above circular structure (see Figure 4) shows that formative assessment is more effective in developing critical thinking as teacher feedback is more important than the mark given to an assessment. Hence, an opportunity for feedback before the final draft of an assignment can be useful in the process of encouraging deep thinking. These opportunities can be maximized by allowing students submitting an argument map [34] of an essay or a plan of an essay for feedback. A study by Devereux and Wilson [10] 
found students face difficulties in identifying weak and strong arguments against a particular dilemma. Peer review exercises can be an alternative strategy to challenge students' on their thinking. As Sadler [30] alerts, little learning can take place without students' receiving regular and effective feedback and thus, students need to develop measures to understand and respond to feedback. Sadler emphasizes the need for teachers developing an appraisal strategy for students to respond to feedback.

As confirmed by this study and many other studies giving effective feedback is time consuming and challenging. In order to give feedback and encourage students' act on feedback, teachers need effective strategies.

... it would be useful if somebody
knows about how to entice students to
act on feedback. I mean, the reasons
why they don't act on feedback vary. It
could be that they don't understand
the feedback well enough to act on it,
and that may be the case in some
instances. It may be that they're too
lazy" (P 13).

Therefore, this study has seen a crucial need for developing effective strategies to give feedback and encourage students to act on feedback and to promote deep thinking skills.

Teachers have difficulties in developing critical thinking in multilevel classes, as multiple intelligences, students' limited skills in reading and writing and students' experience in completing tasks that involve higher order thinking can impact their teaching. While some research argues the importance of scaffoldings [10], [35], some participants in this study believed too much scaffolding can hinder independent learning, thus scaffolding is not necessary for every student. Students should be adequately prepared by providing basic reading and writing skills to direct deep thinking. They should be exposed to higher level activities in their high school education.

The participants in this study were eager to know about effective strategies for developing critical thinking and thought they adopt a personalized pedagogy shaped by their beliefs and experience. Some were positive about the effectiveness of their strategies and tend to avoid using other approaches. This level of risk-aversion can generate limited opportunities to move forward in developing effective strategies. This illustrates the need for effective collaboration within and between disciplines to allow more opportunities for reflection of teaching pedagogies and learning from each other.

\section{Conclusion}

Despite the limitations of a relatively small sample, the study has revealed interesting findings about teachers' perceptions of critical thinking and their strategies for cultivating such skills in academia. One finding is that critical thinking is a metacognitive skill that can be cultivated both in a generic sense and a disciplinary specific sense. The informants in this study did not find domain specific differences in their pedagogies and many strategies discussed in this paper can be used across disciplines. One significant part of critical thinking is students' ability to transfer learning and their skills in disciplinary contexts, workplace and society.

Academics in the study use a wide range of activities to cultivate students' critical thinking: among them written tasks are dominant and teacher feedback seems to add immense value in developing critical thinking. The study found that holistic tasks that provide better opportunities get teacher feedback are necessary for cultivating critical thinking. Students can benefit from effective teacher feedback. While some tasks allow opportunities for complementary feedback, other tasks conclude the learning process only by an assessment of students' work. Hence, the findings show that formative assessment is more useful in developing critical thinking compared to summative assessment. It is important for teachers to 'open and close' the feedback loop for students to benefit from teacher feedback. Otherwise, students are not often encouraged to act on teacher feedback.

Out of many teacher related and student related challenges, the study highlights students' limited reading and written communication skills as major constrains of cultivating adequate level of critical thinking and promoting independent learning. Students' entry levels skills are not satisfactory in most disciplines to guarantee their post entry level skills. This highlights a crucial need for developing students' advanced reading and writing skills, particularly paying attention to genre specific differences in academic disciplines.

The study also demonstrates the need for consolidation and collaboration between and within disciplines in curriculum planning and implementation of pedagogies to allow academics understand the need for students developing transferable critical thinking skills, and disciplinary specific conditions. Academics need to challenge students' thinking to help them to become selfregulated learners. They also should engage in "purposeful reflective practice" [18] to develop excellence in teaching. 


\section{Acknowledgments}

I thank the academics who volunteered to participate in this and study. My thanks should go to the rector's start up grant project at UNSW Canberra for providing funds for this project. I thank associate professor Paul Tranter for his useful comments. I also thank my colleagues, Linda Devereux and Neda Akbari for their useful feedback.

\section{References}

[1] Atkinson, D., (1997). A critical approach to critical thinking in TESOL. TESOL Quarterly, 31 (1), 71- 94.

[2] Barnett, R., (1994). The Limits of Competence: Knowledge, Higher Education and Society. Buckingham: Society for Research into Higher Education/Open University Press.

[3] Behar-Horenstein, L., and NIu, L., (2011). Teaching Critical Thinking in the Higher Education: review of the Literature. Journal of College Teaching and Learning, 8 (2), 25-41.

[4] Borg, S., (2006). Teacher cognition and language education. London: Continuum.

[5] Cameron, I., (2013). Teaching problem solving in engineering. LTG seminar paper presented at UNSW Canberra.

[6] Cohen, L., Manion, L. \& Morrison. K. (2000). Research methods in education (5th edition). New York: Routledge.

[7] Council, A., Q., F., (2013). Australian qualifications framework.http://www.aqf.edu.au/wpcontent/uploads/2013/05/AQF-2nd-Edition-January2013.pdf retrieved on 15.06.14.

[8] Daley, B., J., Shaw, C, R., Balistrieri, T., Glasenapp, K. \& Piacentine, L., (1999). Concepts maps: A strategy to teach and evaluate critical thinking. Journal of Nursing Education, 38(1). 42-47.

[9] Daud, N., M,. and Husin, Z., (2004).Developing critical thinking skills in computer-aided extended reading classes. British Journal of Educational Technology, 35 (4),477487.

[10] Devereux, L., \& Wilson, K., (2008). Scaffolding literacies across the Bachelor of Education program: a course-wide approach, Asia-Pacific Journal of Teacher Education, 36(2), 121-134.

[11] Ennis, R., H., (1987). A taxonomy of critical thinking abilities and dispositions. In J. Baron \& R.

[12] Ennis, R., H., (1989). Critical thinking and subject specificity: clarification and needed research. Educational Researcher, 18 (3), 4-10.
[13] Fox, D., (1983). Personal theories of teaching. Studies in Higher Education, 8, 151-163.

[14] Gunawardena, M., and Petraki, E., (2014). Critical thinking in the EAP classroom: Tensions and challenges in the Sri Lankan context.

[15] In Liyanage, I., and Walker, T., Globalizing EAP practice: Negotiating tensions and challenges (Eds). Sense Publishers: Australia.

[16] Halpern, D., F., (1998). Teaching critical thinking for transfer across domains: Disposition skills, structure training and metacognitive monitoring. American Psychologist, 53(4), 449-455.

[17] Kahneman, D., (2011). Thinking Fast and Slow. Farrar, Straus and Giroux: New York, USA.

[18] Kane, R., Sandretto, s., and Heath, C., (2004). An investigation into excellent tertiary teaching: Emphasising reflective practice. Higher Education, 47, 283-310.

[19] Kennedy, M., Fisher, M. B., and Ennis, R., H., (1991). Critical thinking: Literature review and needed research. In Idol, L. \& Jones, B. F. (Eds). Educational values and cognitive instruction: Implications for reform. Hillsdale, NJ: Erlbaum.

[20] Leki, I., and Carson, J., G., (1994). Students' perceptions of EAP writing instruction and writing needs across the disciplines. Tesol Quarterly, 28(1), 81-101.

[21] Lipman, M. (1998). Critical thinking: what can it be? Educational Leadership, 38-43.

[22] Lythcott, J., (1990). Problem solving and requisite knowledge of chemistry. Journal of Chemical Education, 67(3) 248-252.

[23] McLoughlin, C., and Luca, J., (2000). Cognitive engagement and higher order thinking through computer conferencing: We know why but do we know how? Teaching and learning forum proceeding content:

[24]McPeck, J., (1981). Critical thinking and education. New York: St Martin's Press.

[25] Moore, T., (2011). Critical thinking and disciplinary thinking: a continuing debate. Higher Education Research \& Development, 30 (3), 261-274.

[26] Norman, G., R., \& Schmidt, H., G., (1992). The psychological basis of problem based learning. Academic Medicine, 67 (9), 557-565.

[27] Pithers, R., T., and Soden, R., (2000). Critical thinking in education: a review. Educational Research, 42 (3), 237-249.

[28] Ramsden, P,. (1992). Learning to teach in higher education. London: Routlege.

[29] Raths, L., E., Wasserman, S., Jonas, A., and Rothstein, A., (1966). Teaching for critical thinking: Theory and application. Columbus, Ohio: Charles-Merrill. 
[30] Sadler, D., R., (2010). Beyond feedback: Developing student capability in complex appraisal. Assessment \& Evaluation in Higher Education, 35(5), 535-550.

[31] Sternberg (Eds.), Teaching thinking skills ,(pp. 9-26). New York: W.H. Freeman.

[32] Sternberg, R., J., (1986). Critical Thinking: Its Nature, Measurement, and Improvement.http://files.eric.ed.gov/ fulltext/ED272882.pdf, retrieved on 03.04.14

[33] Tapper, J., (2004). Student perceptions of how critical thinking is embedded in a degree program. Higher Education Research \& Development, 23 (2), 199-222.

[34] Twardy, C., (2004). Argument maps improve critical thinking. Teaching Philosophy, 27(2), 95-116.

[35] Wass, R., Harland, T. and Mercer, A., (2011). Scaffolding critical thinking in the zone of proximal development. Higher Education Research \& Development, 30 (3), 317-328.

[36] Polya, G., (1957). How to solve it. Penguin books: London. 